\title{
PENGARUH PENERAPAN MODEL PEMBELAJARAN KOOPERATIF TIPE NUMBERED HEAD TOGETHER DIPADU CONTEXTUAL TEACHING AND LEARNING TERHADAP HASIL BELAJAR SISWA SMA IMANUEL PALU
}

The Influence of Application of Cooperative Learning Model Type Numbered Head Together combination with Contextual Teaching and Learning toward Learning Outcomes of Students in SMA Imanuel Palu

\author{
*Lika Yulinda, Kasmudin Mustapa dan Ratman \\ Pendidikan Kimia/FKIP - Universitas Tadulako, Palu - Indonesia 94118 \\ Received 12 March 2018, Revised 13 April 2018, Accepted 11 May 2018
}

\begin{abstract}
This study aim was to determine the influence of application of cooperative learning model type numbered head together combination with contextual teaching and learning toward learning outcomes of students in SMA Imanuel Palu. This study used quasi experimental design with non randomized pretest-posttest control group. Sample used were two classes, $X b(n=30)$ as experimental and $X a(n=30)$ as control one. The test of student learning outcomes data used the t-test statistical analysis of the two parties. The results of data analysis obtained, the average score of experimental class $\left(\bar{X}_{1}\right)$ was 50.50 with a standard deviation of 9.79 and for control class ( $\overline{\mathrm{X}}_{2}$ ) was 41.03 with a standard deviation of 11.01. The result of testing hypothesis with the statistical t-test of two parties obtained that $-t_{\text {table }}<t_{\text {calculation }}>+t_{\text {table }}\left(t_{\text {calculation }}=2.35\right.$ and $\left.t_{\text {table }}=2.00\right)$ with a significance level $\alpha=$ 0.05 and 58 degrees of freedom, then $H_{0}$ was rejected and $H_{a}$ was accepted. The result of the data analysis showed that there was any in learning outcomes between students in experimental class and the control class, until concluded there is any influences of application of cooperative learning model type numbered head together combination with contextual teaching and learning toward learning outcomes of students in SMA Imanuel Palu.
\end{abstract}

Keywords: Influence, cooperative learning, numbered head together, contextual teaching and learning, learning outcomes

\section{Pendahuluan}

Pengertian pendidikan menurut UndangUndang Sistem Pendidikan Nasional (UUSPN) No.20 Tahun 2003 menyatakan bahwa, pendidikan adalah usaha sadar dan terencana untuk mewujudkan suasana belajar dan proses pembelajaran agar peserta didik secara aktif mengembangkan potensi dirinya untuk memiliki kekuatan spiritual keagamaan, pengendalian diri, kepribadian, kecerdasan, akhlak mulia, serta keterampilan yang diperlukan dirinya, masyarakat, bangsa dan negara (Suryani, 2013). Keaktifan peserta didik seperti yang diungkapkan tersebut sangat ditentukan oleh peran guru dalam proses pembelajaran.

Menurut Isjoni (2010) dalam pelaksanaan pembelajaran dengan cooperative learning, guru adalah sebagai fasilitator, mediator, directormotivator, dan evaluator. Sebagai fasilitator, seorang guru harus memiliki sikap-sikap sebagai berikut: 1) mampu menciptakan suasana kelas yang nyaman dan menyenangkan; 2) membantu

*Correspondence

Lika Yulinda

Program Studi Pendidikan Kimia, Fakultas Keguruan dan Ilmu Pendidikan, Universitas Tadulako e-mail: : likayulindabombong19@gmail.com

Published by Universitas Tadulako 2018 dan mendorong siswa untuk mengungkapkan dan menjelaskan keinginan dan pembicaraannya baik secara individual maupun kelompok; 3) membantu kegiatan-kegiatan dan menyediakan sumber atau peralatan serta membantu kelancaran belajar mereka; 4) membina siswa agar setiap orang merupakan sumber yang bermanfaat bagi yang lainnya; dan 5) menjelaskan tujuan kegiatan pada kelompok dan mengatur penyebaran dalam bertukar pendapat.

Menurut Miaz (2015) guru harus memilih strategi pembelajaran yang tepat dan relevan dengan tujuan pembelajaran. Faktanya, dari hasil observasi peneliti selama ini belum semua guru yang mampu menerapkan berbagai macam model pembelajaran. Guru lebih cenderung menggunakan model konvensional dengan metode ceramah dalam proses pembelajaran yang mengakibatkan guru mendominasi pembelajaran sehingga siswa hanya mendengarkan dan mencatat tanpa melakukan banyak aktivitas. Hal itu juga menyebabkan siswa menjadi cepat jenuh, kurang bersemangat dan tidak tertarik pada pembelajaran.

Permasalahan lain yang dihadapi oleh guru ialah masih banyak ditemui siswa yang kurang tertarik pada materi pelajaran karena tidak memahami tentang kaitan materi yang dipelajari dengan kehidupan sehari-hari. Menurut guru pengampu mata pelajaran tersebut di SMA Imanuel Palu saat melakukan observasi, materi 
reaksi redoks merupakan materi yang sulit untuk dipahami siswa. Wawancara peneliti dengan guru mata pelajaran kimia mengatakan bahwa penyampaian materi telah diusahakan dengan baik dan jelas, namun dirasa kurang maksimal karena penyampaian materi seharusnya dikaitkan dengan konteks kehidupan nyata dalam kehidupan seharihari agar siswa lebih tertarik pada proses pembelajaran karena mengetahui makna dari materi pelajaran yang diajarkan.

Kristiawan (2013) menyatakan bahwa model pembelajaran kooperatif memiliki kontribusi yang dapat diberikan untuk pengembangan keterampilan sosial siswa dan bekerjasama dengan siswa lainnya. Hal ini juga membantu siswa untuk mengembangkan kemampuan empatik mereka, dan mencoba untuk menemukan solusi untuk masalah dalam kelompok juga mengembangkan keterampilan seperti kebutuhan untuk mengakomodasi pandangan orang lain.

Model pembelajaran kooperatif terdiri atas beberapa tipe, salah satunya ialah numbered head together (NHT) atau penomoran berpikir bersama (Ramadhan, dkk, 2014). NHT merupakan jenis pembelajaran kooperatif yang dirancang untuk mempengaruhi pola interaksi siswa dan sebagai alternatif terhadap struktur kelas tradisional. Kagan (1993) pertama kali mengembangkan NHT untuk melibatkan lebih banyak siswa dalam menelaah materi yang tercakup dalam suatu pelajaran dan mengecek pemahaman mereka terhadap isi pelajaran tersebut (Trianto, 2009). Selain model pembelajaran NHT, dikenal pula model pembelajaran contextual teaching and learning (CTL) yang merupakan suatu proses pembelajaran holistik bertujuan untuk membelajarkan peserta didik dalam memahami bahan ajar secara bermakna (meaningfull). Pembelajaran seperti ini berkaitan dengan konteks kehidupan nyata, lingkungan pribadi, agama, sosial, ekonomi, maupun kultural yang menyebabkan peserta didik memperoleh ilmu pengetahuan dan keterampilan yang dapat diaplikasikan dan ditransfer dari satu konteks permasalahan yang satu ke permasalahan lainnya (Hanafiah \& Suhana, 2009).

Melihat konsep model pembelajaran kooperatif dan kontekstual, dengan dasar inilah yang mendorong peneliti untuk melakukan penelitian dengan mengenai pengaruh penerapan model pembelajaran kooperatif tipe numbered head together dipadu contextual teaching and learning terhadap hasil belajar siswa di SMA Imanuel Palu. Pelaksanaan model pembelajaran kooperatif tipe NHT dipadu CTL, diharapkan siswa lebih mudah memahami materi yang dipelajari dan hubungannya dengan kehidupan sehari-hari, agar tercipta proses pembelajaran yang menyenangkan dan efektif. Guru tidak lagi mendominasi jalannya proses pembelajaran namun, siswa yang dituntut lebih aktif dalam proses pembelajaran. Apabila hal ini dapat terwujud dalam kelas pembelajaran, maka diharapkan akan berpengaruh pada peningkatan hasil belajarnya. Tulisan ini untuk mendeskripsikan pengaruh model pembelajaran kooperatif tipe numbered head together dipadu contextual teaching and learning terhadap hasil belajar siswa SMA Imanuel Palu.

\section{Metode}

Jenis penelitian ini adalah quasi eksperiment dengan desain non randomized pretest-posttest control group design. Populasi penelitian ini adalah semua siswa kelas $\mathrm{X}$ sebanyak dua kelas dengan teknik pengambilan sampel adalah metode sampling jenuh. Sampel yang digunakan yaitu siswa kelas Xb $(\mathrm{n}=30)$ sebagai kelas eksperimen dan siswa kelas Xa $(\mathrm{n}=30)$ sebagai kontrol.

\section{Instrumen penelitian}

Instrumen yang digunakan dalam penelitian ini adalah tes hasil belajar terdiri dari 20 soal pilihan ganda dengan 5 item yang valid. Tes hasil belajar bertujuan untuk mengetahui ada tidaknya pengaruh penerapan model pembelajaran kooperatif tipe numbered head together dipadu contextual teaching and learning terhadap hasil belajar siswa SMA Imanuel Palu.

Penelitian ini ditempuh dalam tiga tahap yaitu tahap persiapan, tahap pelaksanaan, dan tahap akhir

\section{Tehnik analisa data}

Data hasil penelitian dianalisis dengan metode analisis statistik deskriptif dan statistik inferensial. Mengukur efektivitas suatu pembelajaran berdasarkan adanya peningkatan dari pretest ke posttest maka digunakan uji $N$-Gain untuk mengetahui kriteria normalisasi gain yang dihasilkan (Meltzer, 2002).

\section{Hasil dan Pembahasan}

Berdasarkan penelitian yang dilakukan maka diperoleh data tentang hasil belajar siswa kelas eksperimen dan kelas kontrol, seperti pada Tabel 1.

Tabel 1: Perbandingan hasil belajar siswa kelas eksperimen dan kontrol

\begin{tabular}{ccc}
\hline \multirow{2}{*}{ Uraian } & \multicolumn{2}{c}{ Tes Akhir } \\
\cline { 2 - 3 } & Kelas eksperimen & Kelas kontrol \\
\hline Sampel & 30 & 30 \\
Nilai terendah & 35 & 25 \\
Nilai tertinggi & 80 & 70 \\
Skor rata-rata & 50,50 & 41,03 \\
Standar deviasi & 9,79 & 10,01 \\
\hline
\end{tabular}

Berdasarkan Tabel 1 dapat dilihat bahwa skor rata-rata pada kelas eksperimen lebih tinggi dibandingkan pada kelas kontrol, hasil posttest yaitu nilai terendah 35 pada kelas eksperimen, pada kelas kontrol 25, untuk nilai tertinggi pada kelas eksperimen 80 dan kelas kontrol 70 sedangkan untuk skor rata-rata nilai posttest pada kelas eksperimen 50,50 dengan standar deviasi 9,79 dan kelas kontrol 41,03 dengan standar deviasi 10,01. Hal ini menunjukan bahwa hasil belajar yang diperoleh pada kelas eksperimen lebih baik dibanding pada kelas kontrol sehingga hal 
tersebut membuktikan bahwa ada peningkatan hasil belajar siswa dengan penerapan model pembelajaran kooperatif tipe NHT dipadu CTL.

Uji $N$-gain bertujuan untuk melihat gambaran tentang pencapaian masing-masing variabel yang terdiri atas 2 variabel dengan menentukan hubungan nilai pretes dan postes pada kelas eksperimen maupun kelas kontrol (Thaib, 2015). Pengujian $N$-gain yang diperoleh disajikan pada Gambar 1.

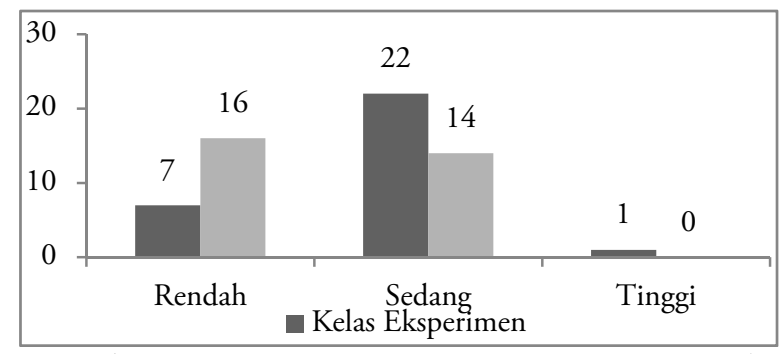

Gambar1: Diagram pengujian $N$-Gain siswa pada kelas eksperimen dan kelas kontrol

Berdasarkan Gambar 1 menunjukan bahwa ada perbedaan peningkatan hasil belajar antara kelas eksperimen dan kelas kontrol, dimana dapat dilihat pada kelas eksperimen kriteria nilai terendah 7 orang, pada kelas kontrol 16 orang, untuk kriteria sedang kelas eksperimen 22 orang, kelas kontrol 14 orang, dan untuk kriteria tinggi pada kelas eksperimen 1 orang dan kelas kontrol tidak ada. Hasil ini menunjukan bahwa model pembelajaran kooperatif tipe NHT dipadu CTL memberikan hasil belajar yang lebih baik dibandingkan pada siswa yang menggunakan model pembelajaran konvensional.

Analisis statistik inferensial digunakan untuk menguji hipotesis yaitu uji-t dua pihak dengan kriteria pengujian $-t_{\text {tabel }}<t_{\text {hitung }}>+t_{\text {tabel }}$ dan membuat generalisasi (Sudjana \& Ibrahim, 2012). Sebelum melakukan analisis inferensial dengan menggunakan uji-t dua pihak, terlebih dahulu dilakukan uji prasyrat yaitu uji normalitas dan uji homogenitas. Menurut Herdianto, dkk, (2014) uji normalitas bertujuan untuk menentukan apakah data yang telah diperoleh terdistribusi normal atau tidak. Uji homogenitas digunakan untuk mengetahui apakah data kedua varian kelas adalah homogen atau tidak. Hasil pengujian tersebut disajikan pada Tabel 2.

Tabel 2: Hasil Uji Statistik Terhadap Hasil Belajar Siswa

\begin{tabular}{|c|c|c|c|c|c|c|c|c|}
\hline \multirow{2}{*}{ Kelas } & \multirow{2}{*}{$\mathrm{N}$} & \multicolumn{3}{|c|}{ Uji Normalitas } & \multicolumn{3}{|c|}{ Uji Homogenitas } & \multirow{2}{*}{ Uji t } \\
\hline & & $\chi_{\text {hit }}^{2}$ & $\chi_{\mathrm{tab}}^{2}$ & Kesimpulan & $\mathrm{F}_{\text {hit }}$ & $\mathrm{F}_{\mathrm{tab}}$ & Kesimpulan & \\
\hline Eksperimen & 30 & 6,73 & 7,81 & $\begin{array}{c}\text { Terdistribusi } \\
\text { normal }\end{array}$ & 0,22 & 2,49 & Homogen & $\mathrm{t}_{\text {hit }}=2,35$ \\
\hline Kontrol & 30 & 6,33 & 7,81 & $\begin{array}{c}\text { Terdistribusi } \\
\text { normal }\end{array}$ & 0,22 & 2,49 & Homogen & $\mathrm{T}_{\mathrm{tab}}=2,00$ \\
\hline
\end{tabular}

Tabel 2 menunjukkan hasil perhitungan uji normalitas untuk kelas eksperimen dengan $\chi_{\text {hitung }}^{2}$ yaitu sebesar 6,73 dan $\chi_{\text {tabel }}^{2}$ diperoleh sebesar 7,81 , pada taraf signifikan $\alpha=0,05 \mathrm{dan} \mathrm{dk}=\mathrm{k}-3=6-3$ $=3$, maka dapat disimpulkan bahwa data tersebut berdistribusi normal karena memenuhi kriteria data berdistribusi normal $\chi_{\text {hitung }}^{2} \leq \chi_{\text {tabel yaitu }}^{2} 6,73 \leq$ 7,81. Sedangkan hasil perhitungan kelas kontrol

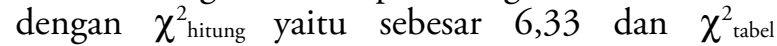
diperoleh sebesar 7,81, pada taraf signifikan $\alpha=$ $0,05 \mathrm{dan} \mathrm{dk}=\mathrm{k}-3=6-3=3$, maka dapat disimpulkan bahwa data tersebut berdistribusi normal karena memenuhi kriteria data berdistribusi normal $\chi_{\text {hitung }}^{2} \leq \chi_{\text {tabel yaitu }}^{2} 6,33 \leq$ 7,81 .

Hasil pengujian homogenitas menggunakan uji F (kesamaan dua varians), dan diperoleh varians tersebesar yaitu 10,01 dan varians terkecil yaitu 9,79 maka nilai $F_{\text {hitung }}=0,22$ dan $F_{\text {tabel }}=2,49$ dengan $\alpha=005$ dan $\mathrm{dk}=(29,29)$, maka dapat disimpulkan bahwa data tersebut memenuhi kriteria data homogen yaitu $\mathrm{F}_{\text {hitung }}<\mathrm{F}_{\text {tabel }}$ yaitu $0,22<2,49$. Data bersifat homogen berarti varians skor yang diukur pada kedua sampel tidak terdapat perbedaan varians antara kelas eksperimen dan kelas kontrol atau memiliki varians yang sama.

Selanjutnya, pengujian hipotesis dengan menggunakan uji-t dua pihak yang bertujuan untuk mengetahui apakah terdapat perbedaan hasil belajar siswa yang menggunakan model pembelajaran kooperatif tipe numbered head together dipadu contextual teaching and learning terhadap hasil belajar siswa SMA Imanuel Palu. Hasil yang diperoleh ialah harga $\mathrm{t}_{(0.95)}$ dengan $\mathrm{dk}=$ 58 dari daftar distribusi siswa adalah 2,00, kriteria pengujian adalah jika $-t_{\text {tabel }} \leq t_{\text {hitung }} \leq+t_{\text {tabel }}(1-\alpha)$, $\left(\mathrm{n}_{1}+\mathrm{n}_{2}-2\right)$ terima $\mathrm{H}_{0}$ dan $\mathrm{Ha}$ ditolak. Berdasarkan hasil diperoleh $-2,00 \leq 2,35 \geq+2,00$ berada pada daerah penolakan $\mathrm{H}_{0}$ sehingga $\mathrm{H}_{0}$ menunjukkan bahwa terdapat perbedaan hasil belajar siswa yang menggunakan model pembelajaran kooperatif tipe numbered head together dipadu contextual teaching and learning terhadap hasil belajar siswa SMA Imanuel Palu dengan model pembelajaran konvensiaonal dengan metode ceramah. Hal tersebut dikarenakan model pembelajaran kooperatif tipe NHT dipadu CTL memiliki tahapan pembelajaran yang dapat menekankan pada partisipasi siswa dan aktivitas siswa untuk mencari sendiri materi pelajaran yang akan dipelajari siswa dan melatih siswa untuk menumbuhkan kemampuan berfikir mandiri ditolak dan $\mathrm{H}_{\mathrm{a}}$ diterima. $\mathrm{Hal}$ tersebut sehingga siswa terlibat secara aktif dalam pembelajaran dari tahap pertama hingga akhir dan siswa lebih mengetahui makna pembelajaran. Keterlibatan siswa secara aktif dapat mempengaruhi hasil belajar siswa. Hal ini sejalan dengan pendapat Susanto (2012) yang menyatakan bahwa pembelajaran menjadi bermakna apabila 
peserta didik terlibat secara aktif dalam proses pembelajaran.

Penerapan model pembelajaran kooperatif tipe NHT dipadu CTL memberikan hasil belajar yang lebih tinggi dibandingkan dengan model pembelajaran konvensional hal ini dikarenakan model pembelajaran kooperatif tipe NHT dipadu CTL memiliki kelebihan. Kelebihan hasil belajar dalam penelitian ini didukung oleh pendapat Utami (2010) yang menyatakan bahwa pembelajaran kooperatif Tipe NHT mempunyai beberapa kelebihan diantaranya: meningkatkan prestasi belajar, rasa ingin tahu, rasa percaya diri, kerja sama, komunikasi antar siswa, dan membantu siswa belajar menggunakan sopan santun serta menghargai pendapat orang lain. Haydon, dkk, (2010) juga menyatakan bahwa NHT merupakan strategi yang lebih efektif jika dibandingkan dengan pembelajaran tradisional. Begitu pula dengan Suprijono (2009) yang menyatakan bahwa pembelajaran kontekstual merupakan prosedur pendidikan yang bertujuan membantu siswa memahami makna bahan pelajaran yang mereka pelajari dengan cara menghubungkannya dengan konteks kehidupan mereka sendiri dalam lingkungan sosial dan budaya masyarakat.

Penggunaan model pembelajaran kooperatif tipe numbered head together dipadu contextual teaching and learning dapat menjadikan siswa mencapai hasil belajar yang baik. Hal ini telah dibuktikan oleh beberapa peneliti terdahulu yaitu penelitian oleh Faristiana (2013) tentang penerapan model pembelajaran kooperatif tipe NHT sebagai upaya peningkatan keaktifan dan hasil belajar. Penggunaan NHT meningkatkan perilaku siswa yang terkesan sebelumnya pasif berubah menjadi lebih aktif. Temuan ini didukung oleh penelitian Misu (2014) yang menyatakan bahwa hasil belajar siswa dalam pembelajaran kooperatif dengan numbered heads together dapat meningkatkan hasil belajar dan dapat memecahkan masalah matematika. Selain itu, penelitian Oktaviansa (2013) tentang pengaruh model pembelajaran CTL terhadap motivasi dan hasil belajar siswa menunjukkan bahwa dengan menggunakan metode CTL maka terdapat pengaruh terhadap hasil belajar siswa dan mengalami peningkatan. Ketuntasan belajar peserta didik mencapai $83 \%$.

Adanya perpaduan antara model pembelajaran kooperatif tipe NHT dipadu CTL mempunyai kelebihan yang selain dapat mendorong siswa untuk terlibat secara aktif, kerjasama antar peserta didik, menumbuhkan rasa ingin tahu dan percaya diri siswa, komunikasi dan belajar untuk menghargai pendapat orang lain, juga dapat memotivasi siswa agar menemukan hubungan antara materi yang dipelajari dengan situasi dunia nyata dan mendorong siswa untuk dapat menerapkannya dalam kehidupan artinya CTL bukan hanya mengharapkan siswa memahami materi yang dipelajari, akan tetapi bagaimana materi pelajaran itu mewarnai perilakunya dalam kehidupan sehari-hari (Kurniadi, 2011).

\section{Kesimpulan}

Terdapat perbedaan hasil belajar siswa kelas eksperimen dan kelas kontrol, sehingga dapat disimpulkan bahwa ada pengaruh penerapan model pembelajaran kooperatif tipe numbered head together dipadu contextual teaching and learning terhadap hasil belajar siswa SMA Imanuel Palu. Hasil belajar yang diperoleh setelah penerapan model pembelajaran kooperatif tipe numbered head together dipadu contextual teaching and learning pada kelas eksperimen diperoleh skor rata-rata 50,50 sedangkan pada kelas kontrol dengan model pembelajaran konvensional skor rata-rata yang diperoleh 41,03. Hal ini memperlihatkan bahwa model pembelajaran kooperatif tipe numbered head together dipadu contextual teaching and learning memiliki hasil yang lebih baik dibandingkan pada kelas kontrol yang menggunakan model pembelajaran konvensional.

\section{Ucapan Terima Kasih}

Penulis mengucapkan terima kasih kepada kepala SMA Imanuel Palu, guru kimia di SMA Imanuel Palu, siswa kelas X SMA Imanuel Palu dan semua pihak yang telah membantu penulis dalam menyelesaikan penelitian ini.

\section{Referensi}

Faristiana, A. (2013). Penerapan model pembelajaran kooperatif tipe numbered head together sebagai upaya peningkatan keaktifan dan hasil belajar sosiologi siswa kelas XI IPS SMA negeri 7 surakarta tahun pelajaran 2012/2013. Surakarta: Universitas Sebelas Maret.

Hanafiah, N. \& Suhana, C. (2009). Konsep strategi pembelajaran. Bandung: PT Rafika Aditama.

Haydon, T., Maheady, L. \& Hunter, W. (2010). Effects of numbered heads together on the daily quiz scores and on-task behavior of students with disabilities. Journal Behaviour Education, 10, 222-238.

Herdianto, K., Suditha, I. W. R. \& Sedanayasa, G. (2019). Pengaruh model pembelajaran MURDER terhadap pemahaman konsep IPA siswa kelas V SD gugus I kecamatan Buleleng. Jurnal Mimbar PGSD Universitas Pendidikan Ganesha, 2(1), 1-10.

Isjoni. (2010). Cooperatif learning Bandung: Alfabeta.

Kristiawan, M. (2013). The implementation of cooperatif learning in english class of favorite school of secondary high school 5, batusangkar, west sumatra. International Journal of Education Administration and Policy Studies, 5(6), 85-90.

Kurniadi. (2011). Pengaruh penerapan pendekatan contextual teaching and learning (CTL) 
terhadap prestasi belajar siswa pada pembelajaran bidang studi PAI kelas VIII di SMP negeri 1 ciganda mekar kabupaten kuningan. Cirebon: Institut Agama Islam Negeri,.

Meltzer, D. E. (2002). The relationship between mathematics preparation and conceptual learning gains in physics: A possible "hidden variable" in diagnostic pretest scores. American Journal Physics, 70, 1259-1268.

Miaz, Y. (2015). The implementation of numbered heads together to improve the students' achievement of social sciences in primary school. Research Journal of Social Sciences, 8(10), 40-45.

Misu, L. (2014). Mathematical problem solving of student by approach behavior learning theory. International Journal of Education and Research, 2(10), 1-15.

Oktaviansa, W. (2013). Pengaruh model pembelajaran ctl terhadap motivasi dan hasil belajar siswa smkn 1 sidoarjo. Jurnal Pendidikan Teknik Mesin, 02(01), 34-43.

Ramadhan, Hasan \& Sumardi. (2014). Menerapkan model pembelajaran kooperatif tipe numbered head together untuk meningkatkan hasil belajar siswa SMK pada mata pelajaran produktif. Journal of Mechanical Engineering Education, 01(01), 1624.

Sudjana, N. \& Ibrahim, A. M. (2012). Penilaian dan penelitian pendidikan. Bandung: Sinar Baru Algesindo.
Sugiyono. (2010). Metode penelitian pendidikan. Bandung: Alfabeta.

Suprijono, A. (2009). Cooperatif learning. Yogyakarta: Penerbit Pustaka Belajar.

Suryani. (2013). Efektivitas pembelajaran kooperatif tipe team-game-tournament (TGT) dan numbered heads together (NHT) terhadap keaktifan dan hasil belajar matematika siswa kelas vii smp muhammadiyah 8 Yogyakarta. Skripsi. Yogyakarta: UIN Sunan Kalijaga.

Susanto, J. (2012). Pengembangan perangkat pembelajaran berbasis lesson study dengan kooperatif tipe numbered heads together untuk meningkatkan aktivitas dan hasil belajar IPA di SD. Journal of Primary Educational, 01(02), 71-77.

Thaib, D. R. (2015). Pengaruh model pembelajaran terpadu tipe nested (tersarang) terhadap hasil belajar siswa kelas xi sma negeri 1 lore utara pada materi termokimia. Skripsi Universitas Tadulako, Tidak diterbitkan.

Trianto. (2009). Mendesain model pembelajaran inovatif-progesif. Jakarta: Prenada Media Group.

Utami, W. (2010). Efektivitas model pembelajaran kooperatif tipe nht (numbered heads together) terhadap hasil belajar tentang tanda-tanda dini komplikasi kehamilan. Skripsi. Surakarta: Universitas Sebelas Maret. 